\title{
Penggunaan Metode Analytical Hierarcy Process dalam Menentukan Kelayakan Sambungan KWH Meter Pelanggan Baru PT.PLN (Persero)
}

\author{
Mustika $^{1^{*}}$, Immanuel Simatupang ${ }^{2}$ \\ ${ }^{1}$ Politeknik Palcomtech Palembang \\ ${ }^{2}$ STMIK Palcomtech Palembang \\ "email:mustika@palcomtech.ac.id
}

\begin{abstract}
One of PT PLN (Persero) service is installation for a new costumer. Demand of installation from 10 until 15 customers every day. Before installation, the surveyor must be certain that installation is feasible or not. Having six criteria for installation namely, power, SLO, size of cable, type of cable, hot spot, and location. The decision support using multiple criteria, can get helped from Decision Support Systems (DSS) application. The purpose of this research is to implemented Analytical Hierarchy Process (AHP) method into DSS analyze to get support installation for a new customers of PT PLN (Persero). The result of implementation method againts study case otherwise satisfy of installation, because it have value grater than of rank Standar Of Procedure (SOP) PT PLN (Persero) S2WJB branch of Rivai Palembang
\end{abstract}

Keywords: analytical hierarchy process, installation kwh meter

\begin{abstract}
Abstrak
Salah satu wujud pelayanan PT.PLN (Persero) adalah pemasangan KWH meter untuk pelanggan baru. Permintaan pemasangan relative banyak setiap hari mencapai 10-15 pelanggan. Sebelum dilakukan pemasangan, surveyor melakukan pengecekan ke lapangan untuk memastikan apakah pemasangan kwh meter tersebut layak atau tidak. Kriteria kelayakan berpengaruh kepada enam kriteria, yaitu daya, SLO, ukuran kabel. Jenis kabel, titik api dan lokasi. Pendukung keputusan yang menggunakan multi kriteria, dapat dibantu dengan aplikasi Sistem Pendukung Keputusan (SPK). Tujuan penelitian ini adalah mengimplementasikan metode Analytical Hierarchy Process (AHP) kedalam analisis SPK untuk mendukung keputusan penentuan kelayakan pemasangan kwh meter bagi pelanggan baru PT.PLN (Persero). Implementasi metode terhadap kasus penelitian didapatlah bahwa input real dinyatakan memenuhi kelayakan untuk pemasangan, dikarenakan memiliki nilai rangking lebih besar dari pada nilai Standar OfProcedure (SOP)PT.PLN (Persero)S2WJB Rayon Rivai Palembang.

Kata kunci: analytical hierarchy process, pemasangan $k$ wh meter
\end{abstract}

\section{Pendahuluan}

Pemasangan baru sambungan listrik merupakan salah satu wujud pelayanan PT. PLN (Persero) kepada pelanggan.PT. PLN (Persero) WS2JB Rayon Rivai Palembang menerima permintaan pemasangan baru sambungan listrik mencapai 10 hingga 15 permintaan per hari. Tahapan dalam proses pemasangan baru sambungan listrik adalah survey lapangan yang dilaksanakan oleh surveyor.

Tujuan dari survey yang dilakukan adalah untuk mengetahui kelayakan sambungan baru (layak atau tidak) untuk dilakukan pemasangan KWH meter yang merupakan alat pengukur dan pembatas (APP).

Penentuan kelayakan sambungan $\mathrm{KWH}$ meter pelanggan baru bersifat multi kriteria, yaitu daya, SLO, ukuran kabel. Jenis kabel, titik api dan lokasi. Pendukung keputusan yang menggunakan multi kriteria, dapat dibantu dengan aplikasi Sistem Pendukung Keputusan (SPK). Penelitian SPK mengenai kelayakan pernah dilakukan oleh; Murti, dkk [1] membuat aplikasi sistem penunjang keputusan kelayakan pemberian pinjaman dengan metode fuzzy tsukamoto, sistem yang dikembangkan dapat mempermudah kaposko 
untuk menentukan keputusan yang akan diambil.Riyanto dan Mahmudi [2] membuat sistem pendukung keputusan penerima Kartu Perlindungan Sosial (KPS) dengan metode SAW (Simple Additive Weighting), keunggulannya adalah kemampuannya untuk melakukan penilaian secara lebih tepat karena didasarkan pada nilai kriteria dan bobot preferensi yang sudah ditentukan, selain itu SAW juga dapat menyeleksi alternatif terbaik dari sejumlah alternatif yang ada karena adanya proses perangkingan setelah menentukan bobot untuk setiap atribut.

Untuk membangun SPK dibutuhkan metode analisis, selain fuzzy tsukamoto dan Simple Additive Weighting (SAW).Metode Analytical Hierarchy Process (AHP)juga dapat digunakan untuk SPK yang menentukan kelayakan.

Rico [3] melakukan analisis kelayakan pengajuan kredit dengan menggunakan metode AHP pada BTPN KCP UMK Petaling, aplikasi ini membantu pimpinan dalam menentukan kelayakan apakah kredit yang diajukan layak disetujui atau tidak.Sundari, dkk [4] merancang sistem penunjang keputusan kelayakan penerimaan pemasangan listrik secara gratis menggunakan metode AHP.

Dipilihnya metode AHP sebagai metode analisis SPK untuk menentukan kelayakan pemasangan KWH Meter bagi pelanggan baru PT. PLN, dikarenakan menurut Lemantara, dkk [5] AHP merupakan analisis yang digunakan dalam pengambilan keputusan dengan pendekatan sistem, dimana pengambil keputusan berusaha memahami suatu kondisi sistem dan membantu melakukan prediksi dalam mengambil keputusan.

\section{Metoda Penelitian}

\subsection{Metode Analytical Hierarcy Process (AHP)}

Menurut Makassau dalam Mustika [6] prinsip kerja metode AHP adalah sebagai berikut :Identifikasi Faktor Penyebab, penyusunan Hirarki, penentuan Prioritas, konsistensi, dan bobot prioritas.

1) Mendefinisikan masalah dan menentukan solusi yang diinginkan.

Penentuan kelayakan pemasangan $\mathrm{KWH}$ meter bagi pelanggan baru terkait dalam beberapa kriteria. Berdasarkan kriteria tersebut tidak semua permohonan pengajuan tersebut dinyatakan layak. Untuk alat bantu mendukung keputusan kelayakan tersebut maka diperlukan alat bantu Sistem Pendukung Keputusan dengan menggunakan metode analisis SPK yaitu AHP.

2) Membuat struktur hierarki yang diawali dengan tujuan utama.

Struktur hierarki dibuat berdasarkan data kompleks tentang form-form yang ada dalam proses survei.

3) Membuat matrik perbandingan berpasangan.

Matrik ini dibuat berdasarkan struktur hirarki yang telah dibuat. Bagaimana perbandingannya antar kriteria sehingga terlihat perbandingan yang jelas untuk proses selanjutnya.

4) Mendefinisikan perbandingan berpasangan Intensitas Kepentingan.

Ada enam jenis intensitas kepentingan dalam proses pendefinisian, sehingga akan dilihat mana kepentingan yang sangat utama dalam pengambilan keputusan.

- 1 berarti kedua elemen sama pentingnya.

- 3 berarti elemen yang satu sedikit lebih penting daripada elemen yang lainnya.

- 5 berarti elemen yang satu lebih penting daripada yang lainnya.

- 7 berarti satu elemen jelas lebih mutlak penting daripada elemen lainnya.

-9 berarti satu elemen mutlak penting daripada elemen lainnya.

-2,4,6,8 berarti nilai-nilai antara dua nilai pertimbangan-pertimbangan yang berdekatan.

5) Menghitung nilai dan menguji konsistensinya. Jika dalam pengambilan nilai tidak konsisten maka pengambilan data diulangi. 
6) Mengulangi langkah 3,4, dan 5 untuk seluruh tingkat hirarki.

7) Menghitung vektor dari setiap matriks perbandingan berpasangan. Penghitungan dilakukan lewat cara menjumlahkan nilai setiap kolom dari matriks, membagi setiap nilai dari kolom dengan total kolom yang bersangkutan untuk memperoleh normalisasi matriks, dan menjumlahkan nilai-nilai dari setiap baris dan membaginya dengan jumlah elemen untuk mendapatkan rata-rata.

8) Memeriksa konsistensi hirarki. Adapun yang diukur dalam Analytical Hierarchy Process adalah rasio konsistensi dengan melihat index konsistensi.Konsistensi yang diharapkan adalah yang mendekati sempurna agar menghasilkan keputusan yang mendekati valid. Walaupun sulituntuk mencapai yang sempurna, rasio konsistensi diharapkan kurang dari atau sama dengan $10 \%$.

\section{Hasil Penelitian}

metode AHP diperlukanuntuk menghitung bagaimana sebuah keputusan ditetapkan dan hasil yang diharapkan dapat membantu mendukung pengambilan keputusan dalam menentukan kelayakan pemasangan KWH meter bagi pelanggan baru PT.PLN (Persero).

\section{a. Struktur hirarki SPK}

Gambar 1 berikut adalah struktur hirarki dari SPK yang dibuat berdasarkan data kriteria yang ada dari PT. PLN (Persero) Rayon Rivai. Penentu kelayakan berdasarkan enam kriteria yaitu daya, SLO, ukuran kabel, jenis kabel, titik api, dan lokasi. Kriteria daya berdasarkan penilaian tingkat daya.Kriteria Surat Layak Operasional (SLO) berdasarkan penilaian ada, sedang diproses atau tidak ada.Kriteria ukuran kabel berdasarkan penilaian $>5 \mathrm{~mm}$ atau < 5mm. Kriteria jenis kabel berdasarkan penilaian NYM, NVA, NYY atau NYHY. Kriteria titik api berdasarkan penilaian $>15$ atau $<15$. Kriteria lokasi berdasarkan penilaian $>10 \mathrm{~mm}$ atau $<10 \mathrm{~mm}$.

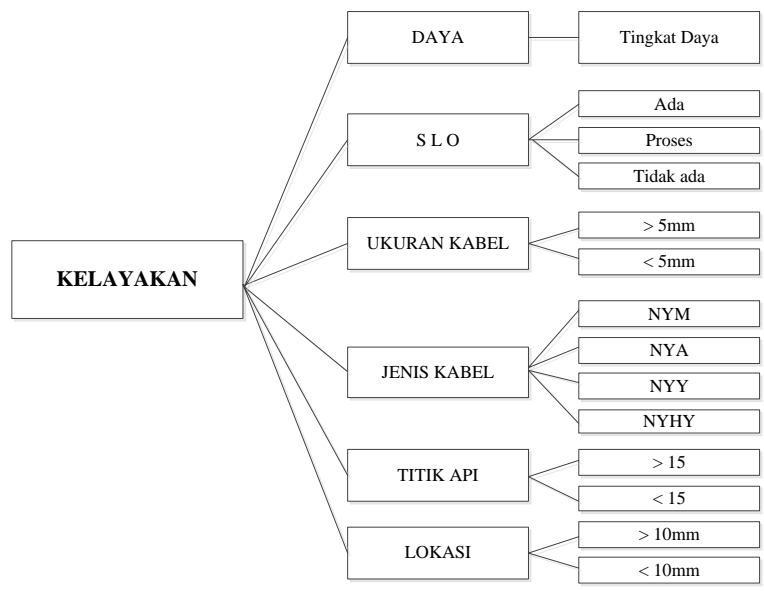

Gambar 1. Struktur Hirarki SPK

\section{b. Membuat Matriks Perbandingan}

Matrik perbandingan dibuat berdasarkan struktur hirarki yang telah dibuat. Bagaimana perbandingannya antar kriteria sehingga terlihat perbandingan yang jelas untuk proses selanjutnya.Sesuai dengan pemberin bobot, pihak PLN memberikan penilaian dari poin 10 sampai dengan poin 100 untuk memberikan penilaian terhadap keputusan pemasangan baru sesuai dengan kriteria yang diberikan.

Tabel 1. Matriks Perbandingan bobot

\begin{tabular}{lcc}
\hline \multicolumn{1}{c}{ BOBOT / } & INPUT REAL & SOP PLN \\
\hline KRITERIA & & \\
SLya & 100 & 50 \\
Ukuran Kabel & 100 & 90 \\
Jenis Kabel & 90 & 80 \\
Titik Api & 90 & 75 \\
Lokasi & 95 & 75 \\
\hline
\end{tabular}

Pada tabel 1 dapat dijelaskan bahwa bobot dan kriteria yang diberikan adalah dua jenis, yaitu bobot yang diberikan oleh pihak PLN yang disebut dengan SOP PLN pada tabel, dan Input Real yang merupakan hasil nyata di lapangan sesuai dengan hasil survei oleh petugas survei.

Pada tabel nilai disesuaikan artinya bahwa nilai tersebut akan diisi sesuai pilihan dari opsi yang ada di sistem yang berlaku. Hal ini menyatakan bahwa nilai hasil masukan oleh surveyor bisa berubah sesuai dengan kriteria yang diisi mereka dilapangan. 


\section{c. Mendefinisikan Intensitas Kepentingan Kriteria}

Tabel 2 adalah tabel keenam jenis intensitas kepentingan dalam proses pendefinisian, sehingga akan dilihat mana kepentingan yang sangat utama dalam pengambilan keputusan.

Tabel 2. Tingkat Kepentingan

\begin{tabular}{cl}
\hline Tingkat & \multicolumn{1}{c}{ Keterangan } \\
\hline 9 & Mutlak lebih penting \\
7 & Sangat lebih penting \\
5 & Lebih penting \\
3 & Cukup penting \\
1 & Sama penting \\
\hline
\end{tabular}

Tabel 3 adalah hasil pemberian intensitas kepentingan oleh pihak PLN yang dilakukan dengan wawancara dan studi kelayakan yang dilakukan penulis kepada bagian distribusi pelayanan di PT. PLN (Persero) Rayon Rivai Palembang.Pemberian intensitas kepentingan merupakan hasil dari perhitungan bersama petugas dan penulis untuk mendapatkan hasil yang baik dengan kondisi yang terbaik untuk mendapatkan keputusan yang akurat.

Tabel 3.Indeks Kepentingan antar Kriteria

\begin{tabular}{|c|c|c|c|c|c|c|}
\hline & DAYA & SLO & $\begin{array}{c}\text { UKURAN } \\
\text { KABEL }\end{array}$ & $\begin{array}{c}\text { JENIS } \\
\text { KABEL } \\
\end{array}$ & TITIK API & LOKASI \\
\hline DAYA & 1 & 7 & 5 & 3 & 3 & 1 \\
\hline SLO & 0.142857143 & 1 & 0.714285714 & 0.428571429 & 0.428571429 & 0.142857143 \\
\hline $\begin{array}{l}\text { UKURAN } \\
\text { KABEL }\end{array}$ & 0.2 & 5 & 1 & 0.6 & 0.6 & 0.2 \\
\hline $\begin{array}{l}\text { KABELL } \\
\text { JENIS } \\
\text { KABEL }\end{array}$ & 0.333333333 & 3 & 3 & 1 & 1 & 0.333333333 \\
\hline $\begin{array}{l}\text { KABEL } \\
\text { TITIK API }\end{array}$ & 0.333333333 & 0.428571429 & 3 & 1 & 1 & 0.333333333 \\
\hline LOKASI & 1 & 0.142857143 & 5 & 3 & 3 & 1 \\
\hline
\end{tabular}

\section{d. Normalisasi}

Penghitungan dilakukan lewat cara menjumlahkan nilai setiap kolom dari matriks, membagi setiap nilai dari kolom dengan total kolom yang bersangkutan untuk memperoleh normalisasi matriks, dan menjumlahkan nilainilai dari setiap baris dan membaginya dengan jumlah elemen untuk mendapatkan rata-rata. Perhitungan dapat dilihat pada tabel 4 .

Tabel 4. Tabel Normalisasi Data

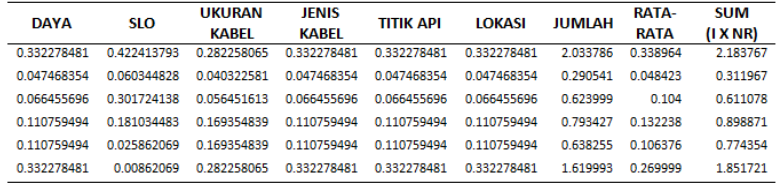

\section{e. Menghitung CI dan CR}

Adapun yang diukur dalam Analytical Hierarchy Process adalah rasio konsistensi dengan melihat index konsistensi.Konsistensi yang diharapkan adalah yang mendekati sempurna agar menghasilkan keputusan yang mendekati valid. Walaupun sulituntuk mencapai yang sempurna, rasio konsistensi diharapkan kurang dari atau sama dengan 10 $\%$.Menghitung CI dengan rumus sebagai berikut :

$$
C I=\frac{\lambda \text { maksimum }-n}{n-1}
$$

Dari hasil normalisasi didapatkan $\lambda$ maksimum adalah jumlah dari (SUM (I x nr)) dibagi dengan Rata-rata dengan nilai 6,615959. Sedangkan jumlah kriteria adalah 6. Sehingga CI adalah

$$
\mathrm{CI}=(6,615959-6) /(6-1)=0,123192
$$

Batas ketidakkonsistenan yang ditetapkan Saaty diukur dengan menggunakan rasio konsistensi (CR), yakni perbandingan indek konsistensi dengan nilai pembangkit random (RI).Nilai RI bergantung pada ordo matrik $n$.

Tabel 4. Tabel Nilai RI

\begin{tabular}{cc}
\hline $\mathbf{N}$ & $\mathbf{R I}$ \\
\hline 1 & 0.00 \\
2 & 0.00 \\
3 & 0.58 \\
4 & 0.90 \\
5 & 1.12 \\
6 & 1.24 \\
\hline
\end{tabular}

CR dirumuskan :

$$
C R=\frac{C I}{R I} \text {. }
$$

Sehingga $\mathrm{CR}$ didapat dengan perhitungan sebagai berikut :

$$
\mathrm{CR}=0,123192 / 1,24=0,099348
$$

Dengan hasil CR yang didapat, dinyatakan bahwa CR lebih kecil dari 0,1 sehingga hirarki dinyatakan konsisten dan dapat diteruskan 
untuk keperluan penghitungan bobot yang diinginkan guna mendapatkan hasil penilaian yang akurat dalam pembuatan keputusan.

Tabel 5. Nilai Setelah Normalisasi

\begin{tabular}{lcc}
\hline \multicolumn{1}{c}{ BOBOT / } & INPUT & SOP PLN \\
KRITERIA & REAL & \\
\hline Daya & 0,5 & 2 \\
SLO & 1 & 0,8 \\
Ukuran Kabel & 1 & 0,888888889 \\
Jenis Kabel & 1 & 0,833333333 \\
Titik Api & 1 & 0,789473684 \\
Lokasi & 1 & 0,5 \\
\hline
\end{tabular}

Tabel 5 adalah tabel nilai input real dan SOP PLN yang sudah dinormalisasi, yang selanjutnya akan diproses dalam tahap perangkingan.

\begin{tabular}{lcc}
\multicolumn{3}{c}{ Tabel 6. Perangkingan } \\
\hline \multicolumn{1}{c}{ BOBOT / } & INPUT & SOP PLN \\
KRITERIA & REAL & \\
\hline Daya & 0,666666667 & 0,333333333 \\
SLO & 0,555555556 & 0,4444444444 \\
Ukuran Kabel & 0,529411765 & 0,470588235 \\
Jenis Kabel & 0,545454545 & 0,454545455 \\
Titik Api & 0,558823529 & 0,441176471 \\
Lokasi & 0,666667 & 0,333333 \\
\hline Total & $\mathbf{0 , 6 1 9 5 1 1 0 6 9}$ & $\mathbf{0 , 3 8 0 4 8 8 9 3 1}$ \\
\hline
\end{tabular}

Berdasarkan tabel 6, yang merupakan tabel perangkingan. Kelayakan pemasangan kwh meter apabila nilai input real lebih besar dari nilai SOP PLN. Maka dalam studi kasus ini, maka input real dinyatakan layak untuk pemasangan kwh meter, dikarenakan nilai input real diatas nilai SOP PLN, yaitu perbandungan nilainya adalah 0,619511069 dengan 0,380488931 .

\section{Kesimpulan}

Sistem Pendukung Keputusan (SPK) dapat digunakan sebagai alat bantusurveyor untuk menentukan kelayakan pemasangan kwh meter untuk pelanggan baru PT.PLN (Persero) S2WJB Rayon Rivai Palembang. Kriteria yang digunakan bersifat multi kriteria yang terdiri dari daya, SLO, ukuran kabel. Jenis kabel, titik api dan lokasi. Hasil dari study kasus yang digunakan memenuhi kelayakan dikarenakan nilai input real lebih besar nilai SOP PLN, yaitu perbandungan nilainya adalah 0,619511069 dengan 0,380488931.

\section{Saran}

Penelitian selanjutnya yang dapat dilakukan adalah mengembangkan metode AHP menjadi aplikasi SPK, yang berbasis mobile.Kajian pustaka menggunakan metode AHP dapat dikembangkan dengan membandingan metode selain AHP, sehingga dapat dianalisis metode analisis mana yang paling ideal untuk menyelesaikan dalam menentukan kelayakan pemasangan kwh meter untuk pelanggan baru PT.PLN (Persero) S2WJB Rayon Rivai Palembang

\section{Daftar Pustaka}

[1] Murti , T., Abdillah, LA., Sobri,M.,"Sistem Penunjang Keputusan Kelayakan Pemberian Pinjaman dengan Metode Fuzzy Tsukamoto", in Seminar Nasional Inovasi dan Tren (SNIT) 2015, 2015, pp. 252-256

[2] Riyanto, E., Mahmudi, "Sistem Pendukung Keputusan Penerima Kartu Perlindungan Sosial(KPS) dengan Metode SAW (Simple Additive Weighting)", in Seminar Nasional Ilmu Komputer (SNIK 2016), 2016, pp. 357364

[3] Rico, "Analisis Sistem Pendukung Keputusan Kelayakan Pengajuan Kredit dengan menggunakan Metode AHP pada BTPN KCP UMK Petaling", Jurnal Media Sistem Informasi, Vol.8, No. 1, pp. 11-21, 2014.

[4] Sundari, SS., Rohpandi, D., Fitri, N., "Sistem Penunjang Keputusan Kelayakan Penerimaan Pemasangan listrik secara Gratis menggunakan Metode AHP", in Seminar Nasional Informatika 2014, 2014, pp. 115-121

[5] Lemantara, J., Setiawan, NA., Aji., NA.,Rancang Bangun Sistem Pendukung Keputusan Pemilihan Mahasiswa Berprestasi Menggunakan Metode AHP dan Promethee. Jurnal Nasional Teknik Elektro dan Teknologi Informasi (JNTETI), Vol. 2, No. 4, 2013, pp. 20-28

[6] Mustika., Penggunaan Metode Analytical Hierarchy Process Dalam Pemilihan Lokasi 
Mangrove Park. Klik-Kumpulan Jurnal Ilmu

Komputer, Vol. 4, No.1, 2017, pp.38-48. 